\title{
On the computation of the geoid-quasigeoid separation
}

\author{
Response to "A strict formula for geoid-to-quasigeoid separation” by Lars Sjöberg
}

\author{
Jakob Flury · Reiner Rummel
}

Published online: 9 February 2011

(C) Springer-Verlag 2011

Modernization of height systems and height reference networks is currently ongoing in many countries. This is, among other reasons, driven by the increasing need to provide precise and well-defined height reference surfaces for GNSS leveling - the geoid for height systems using the orthometric height concept, and the quasigeoid for systems using the normal height concept. Before this background, an ongoing discussion on the geoid-quasigeoid separation seems adequate.

At the core of the discussion is the precise modeling of gravity along the plumbline within topographic masses which is needed to determine each of the quantities geoid, geoid-quasigeoid separation, and orthometric heights. The theory on this problem has been treated by various publications in recent years, see the citations in Flury and Rummel (2009). Sjöberg (2010) suggests modifications to parts of the theoretical formulation. These may be interesting, however, it is not expected that they will result in more than minor effects on the final computation results. We will not further discuss his modifications in this response.

To us, it seems more important to focus on the practical computation, and to analyze the spatial variability of the reference surfaces geoid $(N)$ and quasigeoid $(\zeta)$ and of their separation $\zeta-N$ including the small spatial scales dominated by the contribution of topographic masses. This is very relevant for GNSS leveling using these reference surfaces.

\section{J. Flury $(\varangle)$}

Institut für Erdmessung / Centre for Quantum Engineering and Space-Time Research QUEST, Leibniz Universität, Hannover, Germany

e-mail: flury@ife.uni-hannover.de

\section{R. Rummel}

Institute for Astronomical and Physical Geodesy, Technische Universität München, Munich, Germany

e-mail: rummel@bv.tum.de
Literature on this field has been rather sparse so far, see, e.g., a short summary in Hofmann-Wellenhof and Moritz (2005, p. 384). To some practitioners, the theory on precise modeling may still seem unclear or too difficult to implement, leading them to maintain the concept of simple Helmert orthometric heights. This would mean to, unnecessarily, accept disadvantages such as a "geoid" reference surface which may contain short scale artifacts reaching several decimeters in mountain areas.

In fact, precise modeling of the topographic contribution to the geoid-quasigeoid separation is very well suited for practical computation, and it can easily be implemented. We want to emphasize this point here, hoping that the approach may find more widespread application. The compact formula described in Flury and Rummel (2009)—for which the credit goes back at least to Wirth (1990) —allows to achieve a $\zeta-N$ accuracy of a few centimeters or better very efficiently, based on Bouguer gravity anomalies, a digital terrain model, and a standard topographic mass density. This is considered as a significant progress towards well-defined reference surfaces free of artifacts. Further improvement of accuracy towards a level of $1 \mathrm{~cm}$ may be possible when vertical change of the gravity disturbance (or gravity anomaly) along the plumbline as well as crustal density models are taken into account.

While the precise computation of the topographic contribution is rather simple, the signal properties of the resulting geoid-quasigeoid separation are surprisingly complex and should be well understood. This is another conclusion of Flury and Rummel (2009) which we want to point out more clearly here. Results from our mountain test areas show that in situations with extreme topography, $\zeta-N$ may vary by as much as $1 \mathrm{dm}$ at scales of a few hundred meters. Such extreme topography conditions occur around mountain peaks and crests, but also in gorges and along steep walls, situations which are not uncommon for precision leveling lines. In areas 
with moderate slopes and in broad valleys, the separation is much smoother. A typical feature is that the correlation of $\zeta-N$ is reversed close to the topographic peaks and crests.

This complex small scale variability has to be taken into account to recover $\zeta-N$ with centimeter accuracy, e.g., for GNSS leveling. Results of Flury and Rummel (2009) show that grid models of the geoid-quasigeoid separation should have a mesh width of no more than $200 \mathrm{~m}$ to allow for interpolation with an accuracy of $2 \mathrm{~cm}$ or better in mountains or other areas with steep topography.

\section{References}

Flury J, Rummel R (2009) On the geoid-quasigeoid separation in mountain areas. J Geodesy 83:829-847. doi:10.007/s00190-0090302-9

Hofmann-Wellenhof B, Moritz H (2005) Physical Geodesy, 2nd ed. Springer, Wien

Sjöberg L (2010) A strict formula for geoid-to-quasigeoid separation. J Geodesy 84(11):699-702. doi:10.1007/s00190-010-0407-1

Wirth B (1990) Höhensysteme, Schwerepotentiale und Niveauflächen. Geodätisch-Geophysikalische Arbeiten in der Schweiz vol 42, Swiss Geodetic Commission, Zurich 